\title{
Age and Ethnicity among Hospitalized Alcoholics: A Nationwide Study
}

\author{
B. M. Booth, F. C. Blow, C. A. L. Cook, J. Y. Bunn, and J. C. Fortney
}

\begin{abstract}
Little is known about the broad-scale demographic characteristics of low income or indigent alcoholics in public hospital systems. The purpose of the study was to examine issues relative to age, race/ ethnicity, and marital status for a large group $(n=62,829)$ of alcoholic men receiving inpatient care in Department of Veterans Affairs (VA) medical centers nationally. Subjects were VA inpatients completing alcoholism treatment $(n=27,562)$, in brief alcohol detoxification or short intervention $(n=9,322)$, or hospitalized for primary diagnoses other than alcoholism but with a secondary diagnosis of alcohol dependence syndrome $(n=25,945)$. Minority alcoholics were significantly younger than Caucasian alcoholics. Hispanic and AfricanAmerican men, as well as older alcoholics, were significantly less likely to complete treatment or attend detoxification and more likely to be hospitalized for other primary diagnoses. Native Americans, however, were most likely to complete alcoholism treatment. Results suggest that members of some minority groups and elderly alcoholics seek inpatient care for diagnoses other than alcoholism and that, as a result, such individuals may need targeted interventions to encourage them to seek alcohol-specific care.

Key Words: Demographics, Elderly, Racial/Ethnic Minorities,
\end{abstract} Health Care Utilization.

$\mathbf{A}^{\mathrm{L}}$ COHOLISM IS A major public health problem in the U.S., consuming several billion dollars each year for treatment alone. ${ }^{1}$ Much of the burden of these health care costs falls on the public sector due to the lack of financial resources on the part of many alcoholics. Public funds, from federal, state, and local sources, account for at least $20 \%$ of the treatment costs for alcohol abuse at a variety of institutions and providers. ${ }^{1}$ Given this burden, it is important to understand the characteristics of alcoholics seeking care in public settings for the purposes of planning treatment and other health care programs, evaluating issues of access, and allocating resources. Despite a considerable public investment of resources in health care for alcoholic patients, little is known about patterns of health care utilization or demographic profiles of such patients receiving publicly funded care.

It has been recognized for years that alcoholic patients

From the VA Medical Center, (B.M.B., J.Y.B., J.C.F.) and Center for Health Services Research. The University of Iowa, Iowa City, Iowa (B.M.B.); University of Michigan Alcohol Research Center, Ann Arbor, Michigan. (F.C.B.); and George Warren Brown School of Social Work, Washington University, St. Louis, Missouri (C.A.L.C.).

Received for publication December 17, 1991; accepted May 28, 1992

This study was supported by grants RO1-AA08732 (all authors) and P50-AA07378 (F.C.B.) from the National Institute on Alcohol Abuse and Alcoholism

Reprint requests: Brenda M. Booth, Ph.D., Department of Psychiatry, 4301 W. Markham, Mail Slot 554, Little Rock, AR 72205.

Copyright $(\mathrm{C} 1992$ by The Research Society on Alcoholism. are major consumers of health care resources in the Department of Veterans Affairs (VA) system. ${ }^{2,3}$ For example, in 1985 alone the costs of care for alcohol dependence and abuse in the VA has been reported to be $\$ 188$ million. ${ }^{1}$ Veterans treated in VA Medical Centers (VAMCs) are generally of low income and almost all are provided with health care at no cost. This is largely a result of the eligibility requirements for veterans to receive inpatient VA health services, most recently defined by the Veterans Health Care Amendments Act of 1986 (P.L.99-272). Two groups of veterans are given highest priority for VA health care: those with a service-connected disability and those meeting strict income guidelines according to family size. Because of these eligibility determinations, the VA health care system is likely to treat a higher proportion of the elderly and minority groups than exist in the general population. These groups are generally of lower socioeconomic status and are more likely to seek low cost or free health care.

Sociodemographic information regarding alcoholics and heavy drinkers in the general population is now widely available, courtesy of a number of population surveys. ${ }^{4,5}$ On average, absolute alcohol consumption and prevalence of alcohol abuse decreases dramatically with increasing age, perhaps because of decreased tolerance to alcohol or because of prescribed medications contraindicating alcohol consumption for many older persons. ${ }^{4,6,7}$ AfricanAmericans appear to have higher rates of abstinence, ${ }^{5,8-11}$ similar lifetime prevalence of alcohol abuse/dependence, ${ }^{12}$ but significantly higher mortality rates from cirrhosis of the liver, ${ }^{13,14}$ than Caucasians. Hispanic men have been shown to be heavier drinkers ${ }^{9,15}$ and have higher prevalence of alcohol disorders ${ }^{16}$ than Caucasian or AfricanAmerican men. Elevated mortality rates from injuries, liver cirrhosis, alcoholism, homicide, and suicide have been observed for Native Americans. ${ }^{7,14,17}$

On the other hand, the same kind of information for hospitalized alcoholics is less well studied on a national basis, although frequently available for single sites. ${ }^{18,19}$ One national hospital survey found that hospitalized elderly patients were less likely to have an alcoholism primary diagnosis than younger adults. ${ }^{20}$ Another single site study found that alcohol problems were largely undiagnosed among elderly inpatients. ${ }^{21}$ There is some evidence that African-Americans are less likely to seek formal alcoholism treatment and more likely to seek care for medical illness. ${ }^{7}$ While the rate of hospital discharges for alcohol- 
related illnesses in 1979 was reportedly three times higher for Native Americans than for the general population, ${ }^{7}$ little is known about the nature of these hospitalizations.

A study of alcoholics receiving health care in the VA should provide a unique opportunity to examine issues related to minorities and the elderly, particularly those receiving health care in public hospitals. In particular, we need to know whether groups such as racial/ethnic minorities and the elderly are completing alcoholism treatment or just brief intervention episodes, or whether they are only receiving health care for other medical or psychiatric conditions. The study of alcoholics utilizing the VA should provide insight into broader use by alcoholics of public hospital services or health care that is provided by public health assistance programs such as Medicaid. This study reports age, race, and marital status characteristics of a large sample (approximately 63,000) of alcoholics hospitalized in VA medical centers in relationship to the type of alcohol-related care they received.

\section{METHODS}

\section{Identification of Sample}

The VA has made a major investment in inpatient treatment for alcoholism, establishing a large number of formally designated inpatient Alcohol Dependence Treatment Programs (ADTPs). There were 121 ADTPs in the time interval covered by this study, the federal fiscal year (FY) 1987, October 1, 1986 to September 30, 1987. Data regarding hospitalizations for alcoholic veterans in VA medical centers were obtained from the Patient Treatment File (PTF), the VA's national hospital discharge data base. The PTF contains data regarding each of over one million hospital discharges yearly. Once a patient is discharged from a VAMC, the hospital record is abstracted and coded into electronic format and the resulting data transmitted to a central computer facility in Austin, Texas. Included in the PTF data file are patient demographic characteristics such as age, sex, race, and marital status, and hospitalizationspecific characteristics such as admission and discharge dates, primary and secondary diagnoses for the hospitalization, surgical procedures, and Diagnosis-Related Group (DRG) codes. Also available are data relative to each bedsection occupied during the hospitalization, including specific bedsection diagnoses. Bedsections are grouped by category based on the medical service responsible for the patient's care; they include acute medicine, surgery, and psychiatry, alcoholism and drug treatment, and long-term psychiatry. Patients may be transferred between bedsections during their stay so that if more than one bedsection is occupied, the PTF includes data from each.

The alcoholic sample was identified from the PTF for FY 1987 using a computer algorithm as outlined in Fig. 1 and described in detail below. There were several inclusion and exclusion criteria as presented in Fig. 1 .

In general, the number of women receiving inpatient health care from the VA is small, especially for alcohol-related care. In the time frame covered by this study, there were only 545 alcoholic women compared with approximately 63,000 alcoholic men receiving either alcoholism treatment, detoxification, or other inpatient care from the VA (Fig. 1): Because utilization of psychiatric services differs between men and women ${ }^{22}$ and the number of women was insufficient to conduct separate analyses, the study was restricted to men.

Male patients with either a primary or secondary bedsection diagnosis of alcohol dependence syndrome not coded as "in remission" (ICD9CM codes of $303.90,303.91$, or $303.92^{23}$ ) were studied (Fig. 1). Individuals with a primary diagnosis of drug abuse in FY 1987 were excluded to avoid contamination of the sample with patients whose primary

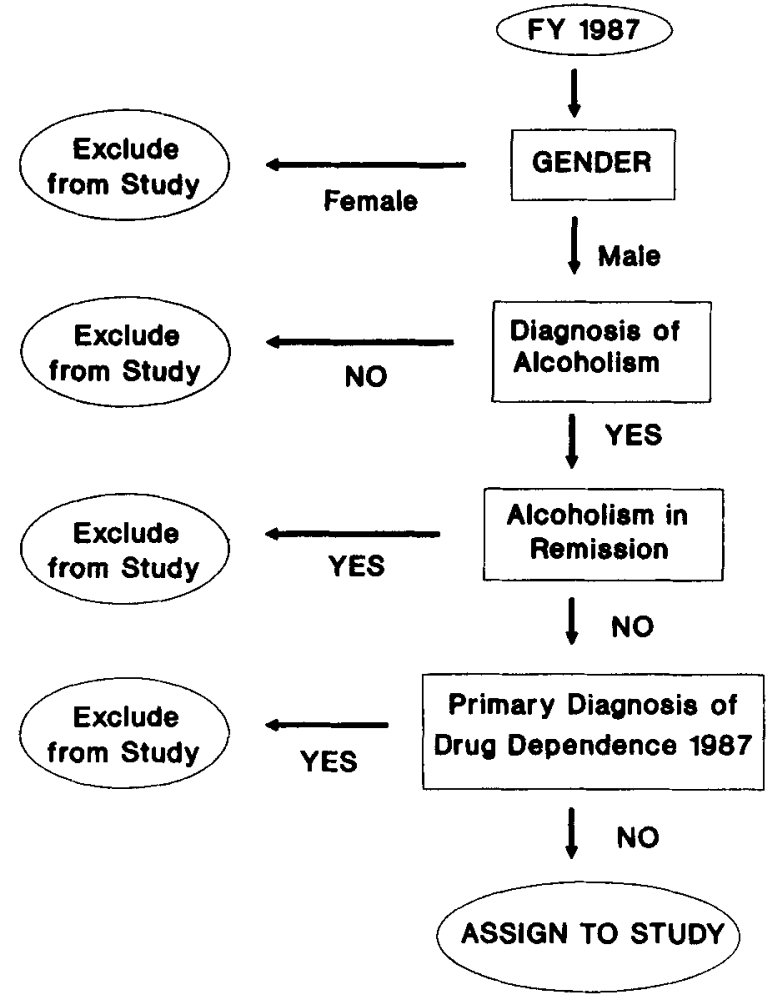

Fig. 1. Process of identification of alcoholic sample from the Patient Treatment File with exclusion/inclusion criteria.

addiction was not alcohol (Fig. 1). One of the purposes of the study was to distinguish between patients receiving formal alcoholism treatment from those receiving only brief detoxification or short intervention episodes and those receiving no specific alcohol-related care. Therefore, patients were classified into one of three treatment groups: (1) completed extended inpatient treatment, (2) brief detoxification or short intervention, and (3) no treatment. Alcohol dependence syndrome was the primary bedsection diagnosis for groups (1) and (2) and the secondary diagnosis in (3). Completion of treatment for group (1) was defined as bedsection length of stay (LOS) to within $10 \%$ of the VAMC's modal LOS (rounded to the nearest day) in an ADTP. Individual VAMCspecific LOS determinations were required because of varying LOS, generally 21 or 28 days, for alcoholism treatment programs among VAMCs. Detoxification (group 2) was defined as a stay of 0 to 5 days. Individuals with LOS more than 6 days in an ADTP but less than $10 \%$ of the modal $\operatorname{LOS}(n=10,898)$ were not studied to avoid mis-classification. Patients were assigned to the no treatment group if they had a secondary diagnosis of alcoholism but were hospitalized for a medical/ surgical or psychiatric primary diagnosis during the year.

Exclusion of alcoholics with a primary diagnosis of drug dependence resulted in elimination of only 4,552 patients, of whom $76.9 \%$ would have been included in the no treatment group, $14.8 \%$ in completed treatment, and $8.3 \%$ in short detoxification. Similarly, identification of alcoholics coded as "in remission" resulted in exclusion of just 2,697 men, of whom $82.9 \%$ would have been assigned to the no treatment group, $13.0 \%$ to the completed treatment group, and $4.1 \%$ to short detoxification. Therefore, these criteria largely affected the no treatment group to exclude individuals with significant drug abuse (most probably those with a concomitant alcohol problem receiving drug abuse treatment on psychiatric units) as well as patients receiving non-alcohol-specific care whose alcoholism was determined to not be current.

Patients with multiple episodes in the fiscal year were assigned to the group denoting the greatest quantity of formal inpatient treatment. For example, if a patient had both a brief alcoholism hospitalization and one in which he completed extended treatment during FY 1987, he was 
assigned to the latter group. The hierarchy was defined in order of the groups as enumerated above. The purpose of this decision was: (1) to identify the most intensive alcoholism-related services an individual received in the year, and (2) to eliminate multiple observations per patient for statistical purposes. Where a single individual had multiple episodes in the same treatment group, one was selected at random. Subsequent analyses found that occurrence of multiple hospitalizations during FY 1987 did not vary substantially by race but was somewhat more likely for the no treatment group and older alcoholics.

\section{Data Analysis}

Patient-specific variables retained for analysis were: age, race, marita status and treatment group. Chi-square tests of independence between pairs of variables were used to test for significant associations. Because the extremely large sample size provided very high power to detect small differences, all tests were significant at the $p<0.05$ level. Therefore, test results are not reported individually. In most circumstances, therefore, it is also important to evaluate whether these are substantive differences.

\section{RESULTS}

\section{Demographic Characteristics of Alcoholics}

The distributions of demographic variables for the alcoholic sample $(n=62,829)$ and the population of all male patients using the VA medical care system (including the alcoholic sample) in FY $1987(n=602,881)$ are presented in Table 1. Male alcoholic veterans were, on average, 10 years younger than all men using VA inpatient hospital services (47.9 years vs. 57.3 years old). In turn, male users of VA health services were somewhat older than the U.S. male veteran population: the 1987 Survey of Veterans (SOVIII) found that $37.2 \%$ of men were at least 60 years old ${ }^{24}$ compared to $53.1 \%$ of VA system users in the same year.

In general, the alcoholic men were less likely to be married than male veterans using the VA $(31.5 \%$ vs. $53.7 \%$, respectively) and, correspondingly, more likely to be divorced, separated, widowed, or never married. The difference in marital status for the alcoholics may be partly

Table 1. Sociodemographic Characteristics of the Male Alcoholic Sample and the VA Male Hospital Population (Fiscal Year 1987)

\begin{tabular}{lrrrrr} 
& \multicolumn{2}{c}{ Alconolic sample } & & \multicolumn{2}{c}{$\begin{array}{c}\text { Hospitalized } \\
\text { population }\end{array}$} \\
\cline { 2 - 3 } \cline { 5 - 6 } & \multicolumn{1}{c}{$N$} & \multicolumn{1}{c}{$\%$} & & \multicolumn{1}{c}{$N$} & $\%$ \\
\hline Age (Mean, so) & 47.9 & $(12.9)$ & & 57.3 & $(14.8)$ \\
$<30$ & 3,775 & $(6.0)$ & & 22,729 & $(3.8)$ \\
$30-39$ & 17,408 & $(27.7)$ & & 81,154 & $(13.5)$ \\
$40-49$ & 12,919 & $(20.6)$ & 62,929 & $(10.4)$ \\
$50-59$ & 14,077 & $(22.4)$ & & 115,496 & $(19.2)$ \\
$60-69$ & 12,270 & $(19.5)$ & 212,458 & $(35.2)$ \\
$\geq 70$ & 2,380 & $(3.8)$ & 108,115 & $(17.9)$ \\
Marital Status & & & & \\
$\quad$ Married & 19,791 & $(31.5)$ & 324,019 & $(53.7)$ \\
Widowed & 3,299 & $(5.3)$ & 43,053 & $(7.1)$ \\
Divorced/separated & 28,795 & $(45.8)$ & 157,385 & $(26.1)$ \\
Never married & 10,944 & $(17.4)$ & 78,424 & $(13.0)$ \\
Ethnic Group & & & & \\
$\quad$ Hispanic & 1,870 & $(3.0)$ & 22,501 & $(3.7)$ \\
$\quad$ Native American & 7773 & $(1.2)$ & 2,619 & $(0.4)$ \\
African-American & 12,820 & $(20.4)$ & 109,331 & $(18.1)$ \\
$\quad$ Caucasian & 47,366 & $(75.4)$ & 468,430 & $(77.7)$ \\
Total sample size & 62,829 & & 602,881 & \\
\hline
\end{tabular}

because the alcoholic sample was younger, but may also be due to decreased social stability related to alcoholism. The married proportions for both the alcoholic sample and VA health care users were much lower than for the U.S. veteran population, in which $79.0 \%$ were married. ${ }^{24}$

The distribution of racial/ethnic groups in the alcoholic groups was generally similar to the distribution for users of VA inpatient health care system. Approximately $25 \%$ of patients studied were from minority racial/ethnic groups, although there were proportionately more Native Americans in the alcoholic sample than in the overall hospitalized population. African-Americans were overrepresented in the VA health care population compared to the U.S. veteran population in the same year (only $8 \%)^{24}$

\section{Relationships Among Sociodemographic Indicators}

Table 2 indicates that there were significantly more nonCaucasian alcoholics among younger patients than in the older age group. There were relatively more Native Americans $(8.3 \%)$ in the under 30 age group than other minorities or Caucasians. While only $25.6 \%$ of Caucasians were 30 to 39 years of age, in contrast $33.7 \%$ of Hispanics, $30.9 \%$ of Native Americans, and $34.4 \%$ of African-Americans were in this age category. On the other hand, $20.8 \%$ of Caucasians were aged 60 to 69 years old, compared with only $13 \%$ to $16 \%$ of the racial/ethnic minority groups.

While only $31.5 \%$ of the overall alcoholic sample was married (Table 1), there were significant differences in marital status (married vs. not married) by age (Table 3 ). Younger men were less likely to be married, with a linear increase in the married proportion with succeeding age intervals. Only $21.7 \%$ of those under 30 were married, $27.9 \%$ of the 30 to 39 year olds were married, $29.1 \%$ and $33.5 \%$ of the 40 to 49 and 50 to 59 year olds, respectively, but $38.4 \%$ and $39.1 \%$ of men 60 to 69 and $70+$ years of age, respectively, were married. There were also variations among ethnic minority alcoholics in rates of being married, with Hispanics most likely to be married $(42.7 \%)$. In contrast, only $29.4 \%$ of Native Americans, $31.0 \%$ of African-Americans, and $31.2 \%$ of Caucasians were married.

\section{Type of Treatment Received}

Of the 62,829 alcoholics identified through the sampling design, $43.9 \%$ completed inpatient alcoholism treatment, $14.8 \%$ participated in detoxification or short intervention, and $41.3 \%$ were in the no treatment group, or were hospitalized for primary diagnoses other than alcoholism. Of the men in the no treatment group, the largest proportions were in acute medicine $(37.2 \%$ of patients in the no treatment group) and acute psychiatry (19.5\%). An additional $6.8 \%$ were in acute surgery; the remaining $36.5 \%$ were distributed across medical and surgical subspecialties, and other psychiatric bedsections such as long-term psy- 
Table 2. Relationship between Age and Race

\begin{tabular}{|c|c|c|c|c|c|c|c|c|c|}
\hline \multirow{3}{*}{$\begin{array}{c}\text { Age } \\
\text { (years) }\end{array}$} & \multicolumn{9}{|c|}{ Ethnic group } \\
\hline & \multicolumn{2}{|c|}{ Hispanic } & \multicolumn{2}{|c|}{ Native American } & \multicolumn{2}{|c|}{ African-American } & \multicolumn{2}{|c|}{ Caucasian } & \multirow{2}{*}{$\underset{N}{\text { Total }}$} \\
\hline & $N$ & $\overline{(\%)^{*}}$ & $N$ & $(\%)$ & $N$ & $(\%)$ & $N$ & $(\%)$ & \\
\hline $40-49$ & 388 & $(20.7)$ & 198 & $(25.6)$ & 2,667 & (20.8) & 9,666 & (20.4) & 12,919 \\
\hline $50-59$ & 426 & $(22.8)$ & 151 & (19.3) & 2,527 & (19.7) & 10,973 & (23.2) & 14,077 \\
\hline $60-69$ & 291 & $(15.6)$ & 98 & (12.7) & 2,028 & (15.8) & 9,853 & $(20.8)$ & 12,270 \\
\hline
\end{tabular}

- Column percent. Totais may not add up to $100 \%$ due to rounding.

Table 3. Relationship between Age and Marital Status

\begin{tabular}{|c|c|c|c|c|c|}
\hline \multirow{3}{*}{$\begin{array}{c}\text { Age } \\
\text { (years) }\end{array}$} & \multicolumn{5}{|c|}{ Marital status } \\
\hline & \multicolumn{2}{|c|}{ Unmarried } & \multicolumn{2}{|c|}{ Married } & \multirow[b]{2}{*}{ Total } \\
\hline & $N$ & $(\%)$ & $N$ & $(\%)$ & \\
\hline$<30$ & 2,955 & (78.3) & 820 & (21.7) & 3,775 \\
\hline $30-39$ & 12,551 & $(72.1)$ & 4,857 & (27.9) & 17,408 \\
\hline $40-49$ & 9,155 & (70.9) & 3,764 & (29.1) & 12,919 \\
\hline $50-59$ & 9,360 & $(66.5)$ & 4,717 & $(33.5)$ & 14,077 \\
\hline $60-69$ & 7,568 & $(61.7)$ & 4,702 & (38.3) & 12,270 \\
\hline$\geq 70$ & 1,449 & $(60.9)$ & 931 & (39.1) & 2,380 \\
\hline
\end{tabular}

* Column percent. Totals may not add up to $100 \%$ due to rounding.

chiatry. The most frequent diagnostic classification in the no treatment group was psychosis unrelated to alcohol consumption, predominantly schizophrenia and schizoaffective disorder (16.7\% of patients in the no treatment group). The second most frequent diagnostic group was "digestive, other" $(11.6 \%)$. This VA classification identifies digestive disorders other than alcohol-related liver disease and abdominal hernias. Next in frequency were "mental, other" $(7.8 \%)$, heart disease $(7.2 \%)$, and alcoholic psychosis (6.8\%). Therefore, two of the three most frequent diagnoses for the men in the no treatment group were psychiatric diagnoses and the third was a group of medical disorders that has some relationship to alcohol consumption. An additional $4.1 \%$ of this group were hospitalized for alcohol-related liver disease. Alcoholics hospitalized with psychiatric primary diagnoses were generally younger than those with medical diagnoses, but there was no clear trend distinguishing medical versus psychiatric hospitalizations by racial/ethnic group.

\section{Sociodemographic Indicators and Type of Treatment}

As shown in Table 4, older men were significantly less likely to receive alcoholism-related services than younger men and more likely to be hospitalized for primary diagnoses other than alcoholism, i.e., be in the no treatment group. Inpatients completing extended alcoholism treatment were also significantly younger than those in detoxification or short interventions. The differences were particularly striking for men older than 60 compared with those younger than 40 years. Two thirds of men in their 60 s and almost $80 \%$ of those at least 70 were in the no treatment group compared with only $28.5 \%$ and $21.0 \%$ of men in their 30s and less than 30, respectively. In contrast, two thirds of alcoholics less than 30 and just over half of those in their 30s were in the completed treatment groups, compared with only a quarter of men in their $60 \mathrm{~s}$ and only $11.7 \%$ of those at least 70 years old. The mean age $( \pm \mathrm{SD})$ of men in the completed treatment group was 44.0 \pm 11.6 years, compared with $46.2 \pm 12.1$ years for those in detoxification or short interventions, and 52.6 \pm 13.0 years in the no treatment group.

Overall, there were relatively fewer married men in the completed treatment group and more married men in the no treatment group (Table 4). These differences may be partly due to the higher concentration of older men, who were more likely to be married, in the no treatment group.

There were significant racial/ethnic differences in type of treatment alcoholics received in FY 1987, as shown in Table 4. Hispanics and African-Americans were least likely to have completed treatment and most likely to be in the no treatment group. Just about half of the Hispanics and African-Americans were in the no treatment group, compared with only a quarter of Native Americans and almost $40 \%$ of Caucasians. On the other hand, Native Americans were most likely to have completed treatment $(64.7 \%)$, followed by Caucasians $(44.7 \%)$.

\section{DISCUSSION}

We studied sociodemographic characteristics for a large group of low income men in relationship to type of inpatient health care, formal inpatient treatment, brief detoxification or short intervention, and hospitalizations for diagnoses other than alcoholism. Results indicate that an extremely large number of alcoholic veterans utilizing VA inpatient services had not participated in any extended inpatient rehabilitation or detoxification program during the year studied. This number was about as many as those completing treatment. However, the database could not provide information to indicate how many in the no treatment group were offered but refused treatment, nor whether they received treatment outside the VA or in other fiscal years. Prospective studies have confirmed that VA alcoholics have very limited financial resources and are largely unemployed. ${ }^{18,19}$ Therefore, few in the no treat- 
Table 4. Demographic Characteristics in Relationship to Treatment Group

\begin{tabular}{|c|c|c|c|c|c|c|c|}
\hline \multirow[b]{3}{*}{ Demographic characteristic } & \multicolumn{7}{|c|}{ Treatment group } \\
\hline & \multicolumn{2}{|c|}{ Complete treatment } & \multicolumn{2}{|c|}{ Short detox } & \multicolumn{2}{|c|}{ No treatment } & \multirow[b]{2}{*}{ Total } \\
\hline & $N$ & $(\%)$ & $N$ & $(\%)$ & $N$ & $(\%)$ & \\
\hline \multicolumn{8}{|l|}{ Age } \\
\hline$<30$ & 2,380 & $(63.1)^{*}$ & 601 & $(15.9)^{\star}$ & 794 & $(21.0)$ & 3,775 \\
\hline $30-39$ & 9,557 & (54.9) & 2,883 & (16.6) & 4,968 & $(28.5)$ & 17,408 \\
\hline $40-49$ & 6,635 & $(51.4)$ & 2,132 & (16.5) & 4,152 & $(32.1)$ & 12,919 \\
\hline $50-59$ & 5,586 & (39.7) & 2,023 & (14.4) & 6,468 & $(45.9)$ & 14,077 \\
\hline $60-69$ & 3,125 & $(25.5)$ & 1,482 & $(12.1)$ & 7,663 & $\{62.4\}$ & 12,270 \\
\hline$\geq 70$ & 279 & $(11.7)$ & 201 & $(8.4)$ & 1,900 & (79.8) & 2,380 \\
\hline \multicolumn{8}{|l|}{ Marital status: Whether married? } \\
\hline No & 19,688 & $(45.7)$ & 6,098 & $(14.2)$ & 17,252 & $(40.1)$ & 43,038 \\
\hline Yes & 7,874 & $(39.8)$ & 3,224 & $(16.3)$ & 8,693 & (43.9) & 19,791 \\
\hline \multicolumn{8}{|l|}{ Ethnic group } \\
\hline Hispanic & 730 & $(39.4)$ & 201 & $(10.7)$ & 939 & $(50.2)$ & 1,870 \\
\hline Native American & 500 & $(64.7)$ & 78 & $(10.1)$ & 195 & $(25.2)$ & 773 \\
\hline African-American & 5,164 & $(40.3)$ & 1,496 & $(11.7)$ & 6,160 & (48.1) & 12,820 \\
\hline Caucasian & 21,168 & $(44.7)$ & 7,547 & (15.9) & 18,651 & $(39.4)$ & 47,366 \\
\hline Total & 27,562 & & 9,322 & & 25,945 & & 62,829 \\
\hline
\end{tabular}

- Row percent. Totals may not add up to $100 \%$ due to rounding.

ment group could have afforded treatment or other inpatient care outside the VA, although many may have utilized low-cost alternatives such as Alcoholics Anonymous.

We found substantial differences in type of inpatient care received by age, confirming earlier reports ${ }^{2,7,20}$ that older alcoholics are less likely to be seen in alcoholism treatment settings and more likely to be hospitalized for medical reasons. This pattern may be a consequence of under-diagnosis, reluctance of formal treatment programs to admit older patients, or inability of older alcoholics to be able to cope with the regimen of treatment. Older alcoholics not receiving treatment may be individuals who have managed to avoid adverse complications of alcohol abuse such as marital conflict, police problems, or job loss and therefore have not been encouraged to enter treatment. This group of older alcoholics, however, may have previously participated in at least one formal alcoholism treatment program, failed, and presented for medical problems common among older individuals in addition to the medical consequences of alcohol abuse. Older alcoholics in our sample did, however, participate in detoxification or short intervention programs with relatively greater frequency than younger alcoholics, suggesting that it may be easier for older alcoholics to be admitted to or function in detoxification or less intensive programs.

Given the concentration of the elderly in the no treatment group and the younger ages of non-Caucasian alcoholics, the number of African-Americans and Hispanics not receiving treatment is even more remarkable. It may be that medical problems associated with alcoholism are appearing earlier in African-Americans and Hispanics, or that these ethnic and racial groups are less inclined to seek treatment. If the relatively low rates of African-Americans and Hispanics in alcoholism treatment have remained the case historically, then the apparently higher rates of medical problems requiring inpatient hospitalization may be a consequence of earlier failures to seek treatment.
On the other hand, a relatively higher proportion of Native Americans completed extended treatment. Native Americans were somewhat younger than Caucasians, but not enough to ascribe the preponderance in treatment to younger age. Perhaps because of greater recognition of alcohol problems among Native Americans, it is easier for them to seek or be encouraged to seek treatment, whereas, in contrast, there is greater reluctance to seek treatment among African-Americans and Hispanics. The lower rates of hospitalizations for diagnoses other than alcoholism may, on the other hand, reflect the higher mortality rates for Native American alcoholics from injuries, suicide, and cirrhosis. ${ }^{17}$ The concentration of younger ages in nonCaucasian alcoholics suggests perhaps earlier mortality for non-Caucasian individuals in general, ${ }^{25}$ and for alcoholics specifically. ${ }^{13,14}$ The younger age of non-Caucasian alcoholics may also be a function of the younger age distribution of African-Americans and Hispanics in the U.S. veteran population. ${ }^{24}$

These results are partially dependent upon the extent of diagnosis and medical record documentation of alcoholism. Under-diagnosis of drinking problems is common. ${ }^{21,26}$ Therefore, the number of alcoholics reported here as not receiving treatment should be interpreted as a considerable underestimate. On the other hand, physician and medical record coding practices may have been such that some alcoholics recorded with active alcoholism should have been coded as "in remission" and thus excluded by our sampling scheme. Whether certain population groups such as the elderly or minorities are more or less likely to have their drinking problems identified remains unknown. The lower participation rates in alcoholism treatment by older and certain racial/ethnic minority groups may be partly a function of lower detection rates for problem drinking.

These results are derived from a relatively socioeconomically homogeneous population of low-income alcoholics 
that should provide insight into users of other public health care institutions or low-income Americans utilizing public funding such as Medicaid. In particular, the data indicate that older alcoholics, African-Americans, and Hispanics may not be receiving adequate alcoholism treatment services. Results of the study particularly highlight the need for targeted assessments for hospitalized elderly and/or minority patients with alcoholism to identify whether alcoholism treatment would be appropriate. Such interventions should reduce the need for later medical hospitalizations related to the consequences of alcohol abuse.

However, in hospitals and health care systems without readily available low-cost or free alcoholism treatment as in the VA, medical care as opposed to alcoholism care may be the only alternative for these population groups. For example, Medicaid coverage for substance abuse treatment is limited and varies substantially by state. ${ }^{27}$ Future research is needed to determine longitudinal patterns of health care utilization by elderly and minority patients in order to understand better the health care needs of these groups of alcoholics and design optimum health care programs.

\section{REFERENCES}

1. Rice DP, Kelman S, Miller LS, Dunmeyer S: The Economic Costs of Alcohol and Drug Abuse and Mental Illness: 1985. DHHS Publication No. (ADM) 90-1694. National Institute on Alcohol Abuse and Alcoholism. Washington DC, US Government Printing Office, 1990

2. Gomberg ES: Prevalence of alcoholism among ward patients in a Veterans Administration Hospital. J Stud Alcohol 36:1458-1467, 1975

3. Page JB: Identifying drinking problems in V.A. hospital patients. J Stud Alcohol 40:447-456, 1979

4. Robins LN, Helzer JE, Weissman MM, et al: Lifetime prevalence of specific psychiatric disorders in three sites. Arch Gen Psychiatry 41:949-958, 1984

5. Herd D: Subgroup differences in drinking patterns among black and white men: Results from a national survey. J Stud Alcohol 51:221232, 1990

6. Myers JK, Weissman MM, Tischler GL, et al: Six-month prevalence of psychiatric disorders in three communities. Arch Gen Psychiatry 41:959-967, 1984

7. Lex BW: Alcohol problems in special populations, in Mendelson JH, Mello NK (ed): The Diagnosis and Treatment of Alcoholism, ed 2. New York, McGraw-Hill, 1985

8. Caetano R: Black drinking practices in Northern California. Am J Drug Alcohol Abuse 10:571-587, 1984

9. Caetano R: Ethnicity and drinking in Northern California: A comparison among whites, blacks, and Hispanics. Alcohol Alcohol $19: 31-44,1984$

10. Colliver J, Grigson MB, Barbano H, et al: NHANES I epidemiological followup study: Methodological issues and preliminary findings, in Spiegler DL, Tate DA, Aitken SS, Christian CM (eds): Alcohol Use Among U.S. Minorities. NIAAA Research Monograph No. 18. DHHS
Publication No. (ADM) 89-1435. Washington DC, US Government Printing Office, 1989

11. Wilson RW, Williams GD: Alcohol use and abuse among U.S. minority groups: Results from the 1983 National Health Interview Survey, in Spiegler DL, Tate DA, Aitken SS, Christian CM (eds): Alcohol Use Among U.S. Minorities. NIAAA Research Monograph No. 18. DHHS Publication No. (ADM) 89-1435. Washington DC, US Government Printing Office, 1989

12. Robins LN: Alcohol abuse in blacks and whites as indicated in the Epidemiologic Catchment Area Program, in Spiegler DL, Tate DA, Aitken SS, Christian CM (eds): Alcohol Use Among U.S. Minorities. NIAAA Research Monograph No. 18. DHHS Publication No. (ADM) 89-1435. Washington DC, US Government Printing Office, 1989

13. Herd D: Migration, cultural transformation and the rise of black liver cirrhosis mortality. Br J Addict 80:397-410, 1985

14. Bertolucci MA, Noble J, Dufour M: Alcohol-associated premature mortality-United States, 1980. JAMA 254:1134-1135, 1985

15. Caetano R: Drinking patterns and alcohol problems in a national sample of U.S. Hispanics, in Spiegler DL, Tate DA, Aitken SS, Christian CM (eds): Alcohol Use Among U.S. Minorities. NIAAA Research Monograph No. 18. DHHS Publication No. (ADM) 89-1435. Washington DC, US Government Printing Office, 1989

16. Burnham MA: Prevalence of alcohol abuse and dependence among Mexican Americans and non-Hispanic whites in the community, in Spiegler DL, Tate DA, Aitken SS, Christian CM (eds): Alcohol Use Among U.S. Minorities. NIAAA Research Monograph No. 18. DHHS Publication No. (ADM) 89-1435. Washington DC, US Government Printing Office, 1989

17. Heath DB: American Indians and alcohol: Epidemiological and sociocuitural relevance, in Spiegler DL, Tate DA, Aitken SS, Christian CM (eds): Alcohol Use Among U.S. Minorities. NIAAA Research Monograph No. 18. DHHS Publication No. (ADM) 89-1435. Washington DC, US Government Printing Office, 1989

18. Schuckit MA, Schwei MG, Gold E: Prediction of outcome in inpatient alcoholics. J Stud Alcohol 47:151-155, 1986

19. McLellan AT, Luborsky L, O'Brien CP, et al: Is substance abuse treatment effective? JAMA 247:1423-1428, 1982

20. Stinson FS, Dufour MC, Bertolucci D: Alcohol-related morbidity in the aging population. Alcohol Health Res World 13:80-87, 1989

21. Beresford TP, Blow FC, Brower KJ, et al: Alcoholism and aging in the general hospital. Psychosomatics 29:61-71, 1988

22. Mechanic D: Medical Sociology, ed 2. New York, The Free Press, $1978, \mathrm{p} 196$

23. World Health Organization: International Classification of Diseases, 9th Revision, ICD-9-CM. Commission on Professional and Hospital Activities, Ann Arbor, MI, 1978

24. Department of Veterans Affairs: 1987 Survey of Veterans. Final report. Washington DC, Department of Veterans Affairs, 1989

25. National Center for Health Statistics: Vital Statistics of the United States, 1986 Vol. II. Sec. 6 Life Tables. DHHS Publication No. (PHS) 88-1 147. Public Health Service, Washington DC, US Government Printing Office, 1988

26. Moore RLD, Bone LR, Geller G, et al: Prevalence, detection, and treatment of alcoholism in hospitalized patients. JAMA 261:403-407, 1989

27. United States General Accounting Office: Substance abuse treatment: Medicaid allows some services but generally limits coverage. Washington DC, General Accounting Office (HRD-91-92), 1991 